'Division of Cardiology, Department of Internal Medicine, University Hospital, Geneva, Switzerland,

${ }^{2}$ Department of Cardiology, University Hospi-

tal, Zurich, Switzerland.

\section{Management of Patients with Carotid Artery Stenosis}

\author{
Marco Roffi', Thomas F. Lüscher ${ }^{2}$
}

\section{Key Words:}

Carotid artery . Endarterectomy . Carotid artery stenting · Carotid stenosis

Herz 2008;33:490-7

DOI 10.1007/ s00059-008-3166-5

\section{Schlüsselwörter:}

Karotisarterie . Endarteriektomie . Karotisstenting · Karotisstenose

\section{Abstract}

A stenosis of the internal carotid artery may cause $10-20 \%$ of all ischemic strokes. Duplex ultrasound is the diagnostic cornerstone, and CT angiography or $M R$ angiography may be used to confirm the severity of the stenosis or prior to revascularization. Catheter-based digital subtraction angiography is rarely needed for diagnostic purposes. In symptomatic patients, carotid revascularization is indicated in the presence of a stenosis $\geq 50 \%$. In asymptomatic patients, the indication for revascularization based on randomized trials is given at $\geq 60 \%$ stenosis, as long as the estimated perioperative death or stroke risk is $<3 \%$. In clinical practice, however, asymptomatic ste-

\section{Management von Patienten mit Karotisstenose}

\section{Zusammenfassung}

Eine Stenose der A. carotis interna ist für 10-20\% aller ischämischen Hirnschläge verantwortlich. Die Duplexsonographie der Karotiden bleibt die wichtigste diagnostische Untersuchung für Patienten mit Verdacht auf Karotisstenose. Die CT-Angiographie oder MR-Angiographie kann zur Bestätigung der Diagnose und vor der Revaskularisation eingesetzt werden. Die invasive Angiographie ist für diagnostische Zwecke selten nötig. Bei symptomatischen Patienten ist eine Revaskularisation der Karotisarterie ab einem Stenosegrad von $50 \%$ indiziert. Bei asymptomatischen $\mathrm{Pa}$ tienten ist die Indikation zur Revaskularisation gemäß den klinischen Studien ab einem Stenosegrad von $60 \%$ gegeben, wenn das perioperative Mortalitätsoder Schlaganfallrisiko auf $<3 \%$ geschätzt wird. Im

\section{Introduction}

In Western countries, stroke is the third most frequent cause of death, behind cardiac disease and cancer, and the number 1 condition associated with permanent disability. A stenosis of the internal carotid artery may be responsible for $10-20 \%$ of all ischemic strokes or transient ischemic attacks (TIAs) [1]. Atherosclerosis is by far the most common pathology underlying carotid artery stenosis, although other disorders such as carotid artery dissection, fibromuscular dysplasia, and Takayasu's arteritis should be considered in the differential diagnosis. Carotid atheroscle- noses are usually treated only if luminal narrowing exceeds $70-80 \%$ and the patient has a life expectancy of at least 5 years. The choice of the revascularization strategy (endarterectomy vs. stenting) should be based on the patient's surgical risk profile and on the locally available expertise. Independently of the revascularization option, carotid artery stenosis patients remain at risk of cardiovascular events because of the high prevalence of associated coronary artery disease. A broad disease management focusing on risk factor and lifestyle modification may impact quality and duration of life of these patients to a greater extent than the revascularization procedure itself.

klinischen Alltag werden aber asymptomatische Stenosen meist ab einem Schweregrad von $70-80 \%$ behandelt, vorausgesetzt der Patient hat eine Lebenserwartung von mindestens 5 Jahren. Die Wahl der Revaskularisationsmethode (Endarteriektomie oder Stenting) sollte auf dem chirurgischen Risikoprofil des Patienten und auf der lokalen Expertise basieren. Unabhängig von der Revaskularisationsmethode bleiben Patienten mit einer Karotisstenose aufgrund der hohen Prävalenz einer koronaren Herzkrankheit mit einem hohen kardiovaskulären Risiko behaftet. Eine breite Behandlungsstrategie, gestützt auf Kontrolle der Risikofaktoren und Änderung der Lebensgewohnheiten, ist in Bezug auf Lebensqualität und Lebenserwartung wahrscheinlich besser wirksam als die Revaskularisation der Karotis.

rosis typically affects the origin of the internal carotid artery but occasionally also the distal common carotid artery. A stenosis is considered symptomatic in the presence of amaurosis fugax, TIA or stroke affecting the corresponding territory in the preceding 6 months. For both symptomatic and symptomatic lesions, the greater the severity of the stenosis, the greater the risk of a (recurrent) ischemic event.

In the North American Symptomatic Carotid Endarterectomy Trial (NASCET), the risk of recurrent stroke in the territory of a symptomatic carotid artery stenosis was $26 \%$ over 2 years (13\%/year) for 
$>70 \%$ stenoses and $18.5 \%$ over 5 years $(4.4 \% /$ year) for $50-69 \%$ stenoses [2]. In asymptomatic patients with a carotid artery stenosis $>60 \%$, the yearly risk of stroke is $\sim 2 \%$ [3]. However, the risk may increase to $3-4 \% /$ year in elderly patients or in the presence of contralateral carotid stenosis or occlusion, carotid plaque heterogeneity, poor collateral blood supply, generalized inflammatory states, and cardiac or medical illnesses [2]. The main mechanism of stroke in patients with carotid artery stenosis is artery-to-artery embolization, although at times hypoperfusion may also play a role.

\section{Diagnosis}

\section{Clinical Presentation}

Asymptomatic carotid disease is usually diagnosed incidentally or following investigation of a neck bruit. However, the detection of a neck bruit is neither sensitive nor specific for the presence of a clinically relevant stenosis of the internal carotid artery. In patients with neurologic symptoms suggestive of brain ischemia, a stenosis at the level of the carotid artery should always be excluded. The differentiation between symptomatic and asymptomatic carotid artery stenosis - challenging at times - is critical because the two conditions may be approached differently. The clinical features of symptomatic carotid disease include retinal ischemia affecting the ipsilateral eye and hemispheric ischemia affecting the contralateral body half. Microembolization to the retina is perceived as amaurosis fugax, a transient monocular loss of vision that affects either the entire eye or the superior or inferior visual fields. Patients will often describe it as a shade coming down or up. Hemispheric ischemia is characterized by a combination of weakness, paralysis, numbness or tingling, all affecting the same side of the body. Aphasia may be present if the dominant
- usually the left - hemisphere is affected. Symptoms not suggestive of symptomatic carotid artery disease include diplopia, ataxia, drop attacks, vertigo, and loss of consciousness. To help adequately interpret symptoms, the involvement of a neurologist is recommended.

\section{Imaging}

An imaging of the carotid arteries should be obtained as soon as possible in all patients presenting with ischemic symptoms potentially related to a carotid source, because the estimated risk of recurrent ischemic event - TIA or stroke - in the 1st month is $10-30 \%$ [4]. The most frequently used imaging modality is carotid duplex ultrasound (DUS), followed by computed tomography angiography (CTA), magnetic resonance angiography (MRA) and transcranial Doppler ultrasound. The DUS velocity criteria to quantify carotid artery stenosis have been described in a recent consensus statement (Table 1) [5]. In high-quality laboratories, sensitivity and specificity for the detection of a severe stenosis of the internal carotid artery exceed $90 \%$. The downside of this imaging modality is that the diagnostic accuracy is operator-dependent. CTA and MRA provide excellent visualization of the intra- and extracranial vessels and may be used if the DUS results are inconclusive, if a revascularization of the carotid artery is planned, or at the time of brain imaging. Catheter-based digital subtraction angiography (DSA) remains the gold standard of carotid imaging. However, because of the overall excellent sensitivity and specificity of noninvasive imaging, DSA is rarely needed for diagnostic purposes. The major drawback of cerebral angiography is the associated stroke risk which has been estimated in recent series at $<1 \%[6]$.

Table 1. Society of Radiology Consensus Panel carotid duplex ultrasound criteria for stenosis estimation (modified with permission from [5]). CCA: common carotid artery; EDV: end-diastolic velocity; ICA: internal carotid artery; PSV: peak systolic velocity.

Tabelle 1. Duplexultraschallkriterien zur Bestimmung des Karotisstenosegrads gemäß Society of Radiology Consensus Panel (mit Genehmigung modifziert nach [5]). CCA: A. carotis communis; EDV: enddiastolische Geschwindigkeit; ICA: A. carotis interna; PSV: systolische Spitzengeschwindigkeit.

\begin{tabular}{|c|c|c|c|c|}
\hline \multirow[t]{2}{*}{ Degree of stenosis } & \multicolumn{2}{|c|}{ Primary parameters } & \multicolumn{2}{|c|}{ Secondary parameters } \\
\hline & ICA PSV (cm/s) & Plaque estimate (\%) & ICA/CCA systolic ratio & ICA EDV $(\mathrm{cm} / \mathrm{s})$ \\
\hline $0 \%$ & $<125$ & None & $<2$ & $<40$ \\
\hline$<50 \%$ & $<125$ & $<50$ & $<2$ & $<40$ \\
\hline $50-69 \%$ & $125-230$ & $\geq 50$ & $2-4$ & $40-100$ \\
\hline$\geq 70 \%$ & $>230$ & $\geq 50$ & $>4$ & $>100$ \\
\hline Near occlusion & Variable & Visible & Variable & Variable \\
\hline Complete occlusion & Undetectable & Visible, no detectable lumen & 0 & 0 \\
\hline
\end{tabular}




\section{Medical Management}

A stenosis of the carotid artery should be considered a marker of advanced systemic atherosclerosis. In this patient population, long-term survival is substantially decreased despite carotid revascularization [7]. Aggressive risk factor modification is recommended in all patients, irrespective of symptoms and revascularization strategy, to limit progression of atherosclerosis and decrease cardiovascular events [8]. Based on the high prevalence of coronary artery disease, a broad disease management may impact quality and duration of life to a greater extent than the revascularization procedure itself [9].

Aspirin is recommended indefinitely in patients with carotid stenosis, irrespective of symptoms. According to the meta-analysis of the Antithrombotic Trialists' Collaboration, patients allocated to antiplatelet therapy had a $16 \%$ risk reduction for fatal stroke and a $28 \%$ risk reduction for nonfatal stroke compared with individuals receiving placebo [10]. In symptomatic patients aspirin is recommended in a dose ranging from 81 to $325 \mathrm{mg} /$ day and there are no data to support higher doses, even in patients with recurrent TIAs on low-dose aspirin. Alternative treatments for symptomatic disease, none of them tested adequately against aspirin in this patient population, include extended-release dipyridamole plus aspirin, clopidogrel, or the combination of aspirin and clopidogrel. Preliminary data on the combination of aspirin and clopidogrel in patients with symptomatic carotid disease are promising. A small randomized trial comparing dual antiplatelet therapy and aspirin alone in 107 patients with symptomatic carotid artery stenosis and Doppler-detectable microembolic signals demonstrated a significant reduction in embolic signals among patients allocated to dual antiplatelet therapy [11]. In a similar study, microembolic signals could be suppressed after administration of a platelet glycoprotein IIb/IIIa receptor inhibitor, suggesting the potential for potent platelet inhibition in this setting [12].

The benefit of lipid-lowering agents - and specifically statins - in patients with systemic atherosclerosis is established. In addition to the lipid-lowering properties, statins have salutary effects on platelet adhesion, thrombosis, endothelial function, inflammation, and plaque stability. The Heart Protection Study demonstrated that simvastatin produced substantial clinical benefits in a wide range of high-risk patients with coronary or vascular disease [13]. The Stroke Prevention with Aggressive Reduction of Cholesterol Levels (SPARCL) study showed that in 4,731 patients with recent stroke or TIA and without known coronary heart disease, high-dose atorvastatin significantly reduced the overall incidence of stroke and of cardiovascular events over 5 years [14]. Al- though studies focusing specifically on patients with carotid artery stenosis are lacking, statin therapy should be administered in all patients with this condition.

The main factor determining the reduction in the incidence of stroke in hypertensive patients is the degree of blood pressure reduction achieved, irrespective of the medication used. Nevertheless, recent trials of angiotensin-converting enzyme (ACE) inhibitors and angiotensin receptor blockers (ARBs) have suggested that the two drug classes may convey a benefit in terms of stroke reduction that extends beyond their antihypertensive effect. The Heart Outcomes and Prevention Evaluation (HOPE) study demonstrated that the ACE inhibitor ramipril significantly reduced the rate of cardiovascular death, myocardial infarction, and stroke in patients at high risk of cardiovascular events [15]. In the Losartan Intervention For Endpoint (LIFE) trial, losartan and atenolol achieved similar degrees of blood pressure reduction, but losartan conveyed a greater reduction in cardiovascular events and stroke [16]. Based on the overall beneficial effect in high-risk vascular patients, ACE inhibitors or ARBs may be considered even in nonhypertensive patients with carotid artery disease.

\section{Carotid Endarterectomy Randomized Trials of Carotid End- arterectomy Versus Medical Management}

Large-scale randomized clinical trials have established the superiority of carotid endarterectomy (CEA) over medical management for stroke prevention in patients with high-grade internal carotid artery stenosis, particularly in the presence of symptoms. Among the 2,226 patients with symptomatic carotid artery stenosis enrolled in NASCET, the ipsilateral stroke rate was reduced from $26 \%$ to $9 \%$ at 2 years in patients with $>70 \%$ stenosis, and the corresponding rate of disabling or fatal stroke was reduced from $13.1 \%$ to $2.5 \%$ [17, 18]. Patients with $50-69 \%$ luminal narrowing benefited from surgery to a lesser but still significant extent, with a decrease in 5-year ipsilateral stroke rates from $22.2 \%$ to $15.7 \%$. Surgical benefit was greatest in men, in patients with hemispheric rather than retinal ischemia, and in individuals with recent stroke rather than TIA.

The benefits of CEA for symptomatic patients were subsequently replicated in the European Carotid Surgery Trial (ECST) enrolling 3,024 patients [19]. A pooled analysis of the two trials reinforced the notion that the degree of stenosis above which surgery was beneficial was $50 \%$, although the benefit in patients with $50-69 \%$ stenosis was substantially less than in those with $\geq 70 \%$ stenosis. In NASCET and ECST, the number needed to treat in patients with 
$>70 \%$ symptomatic stenosis - but no near occlusion - was 6 for ipsilateral stroke or operative death and 14 for disabling ipsilateral stroke or operative death [20].

The Asymptomatic Carotid Atherosclerosis Study (ACAS) trial established the benefit of CEA over medical therapy in 1,662 asymptomatic patients with $60-99 \%$ internal carotid artery stenosis [21]. The risk profile of the population studied was similar to NASCET and again, surgeons and medical centers were highly selected. Specifically, surgeons had to demonstrate a 30-day death or stroke rate following surgery of $<3.0 \%$. The study was terminated early due to improved outcomes in surgically treated patients. The 5-year stroke, including perioperative stroke and death, rate was reduced from $11 \%$ in the medically treated patients to $5.1 \%$ in those treated with CEA. The study had the drawback that it did not follow all patients for the full 5 years but rather extrapolated the data.

One limitation of both NASCET and ACAS was limited use of evidence-based secondary preventive therapies such as statins or ACE inhibitors. The recent Asymptomatic Carotid Surgery Trial (ACST) was able to confirm the benefit of CEA over medical therapy in 3,120 asymptomatic patients with $60-99 \%$ stenosis in the presence of contemporary medical management [19]. At 5 years, the all stroke or death rate was $6.4 \%$ for patients allocated to CEA and $11.8 \%$ for those randomized to medical therapy $(\mathrm{p}<0.0001)$. The ACST also showed that patients subjected to CEA were less likely to have a fatal or disabling stroke $(3.5 \%$ in the surgical group vs. $6.1 \%$ in the conservative arm; $p=0.004)$. Finally, the study showed that most of the benefit was detected among patients aged $<75$ years, while in older asymptomatic patient the benefit of surgery remained uncertain.

\section{Limitations of Carotid Endarterectomy}

The benefits of CEA in the randomized trials were conveyed by low perioperative complication rates (i.e., stroke and death rate of $5.8 \%$ in NASCET and of $2.7 \%$ in ACAS) achieved by high-volume surgeons on low-risk patients. Accordingly, patients with major medical comorbidities (e.g., uncontrolled hypertension or diabetes, severe renal or pulmonary disease, active coronary artery disease) or older than $>80$ years of age, or those with a history of prior ipsilateral endarterectomy, radical neck dissection, radiation therapy to the neck, or contralateral laryngeal nerve palsy, were excluded from the trials. In ACAS, surgeons had to demonstrate a 30-day death or stroke rate following surgery of $<3.0 \%$ to be able to enroll and during the study they were audited in the presence of a high complication rate.

The results of CEA observed in the trials may hardly be reproduced in clinical practice. An analysis involving over 110,000 patients showed that, while within NASCET and ACAS the perioperative mortality for CEA was as low as $0.6 \%$ for symptomatic and $0.1 \%$ for asymptomatic patients, the overall perioperative mortality in the hospitals participating in the trials was $1.4 \%$ [22]. In low-volume hospitals, the perioperative mortality rate was $2.5 \%$. A recent CEA registry from Ontario, Canada, documented a 30-day death or stroke rate of $6.0 \%$ among 6,038 patients undergoing surgery, with an event rate approaching $10 \%$ in high-risk subgroups [23]. Although low operator and hospital volumes have repeatedly been associated with poor outcomes following CEA, in the USA the majority of surgeries are performed by low-volume operators. Accordingly, a recent analysis including over 136,000 CEAs documented a mean volume per operator of 15 procedures per year, while one third of the patients

Table 2. Pros and cons of carotid revascularization procedures (reproduced with permission from [35]).

Tabelle 2. Vor- und Nachteile von Karotisendarteriektomie und Karotisstenting (mit Genehmigung abgedruckt aus [35]).

\begin{tabular}{|c|c|c|}
\hline & Endarterectomy & Stenting \\
\hline Pros & $\begin{array}{l}\text { - Widely available } \\
\text { - Excellent results for high-volume surgeons/hospitals in } \\
\text { low-risk patients }\end{array}$ & $\begin{array}{l}\text { - Outcome less influenced by comorbidities } \\
\text { - Local anesthesia } \\
\text { - No neck incision/scar } \\
\text { - Usually next-day discharge }\end{array}$ \\
\hline Cons & $\begin{array}{l}\text { - Outcome influenced by comorbidities } \\
\text { - Frequently performed in general anesthesia } \\
\text { - Neck incision/scar } \\
\text { - Neck complications, cranial nerve palsies } \\
\text { - Not suitable for high or low carotid lesions } \\
\text { - Longer hospital stay }\end{array}$ & $\begin{array}{l}\text { - Fewer experienced operators } \\
\text { - Risk of the procedure may increase in patients with } \\
\text { - severe peripheral vascular disease } \\
\text { - severely calcified, tortuous/steep aortic arch } \\
\text { - severe calcification or tortuosity of cervicocranial vessels } \\
\text { - Femoral access site complications } \\
\text { - May not be performed in case of aspirin/clopidogrel } \\
\text { intolerance }\end{array}$ \\
\hline
\end{tabular}


were operated on by surgeons with a mean CEA volume of five per year [24]. Advantages and limitations of CEA are reported in Table 2.

\section{Current Indications for Carotid Endarterectomy}

The American Heart Association guidelines [25] support CEA for

- symptomatic patients with $\geq 50 \%$ stenosis of the internal carotid artery,

- asymptomatic patients with $\geq 60 \%$ stenosis of the internal carotid artery, as long as the life expectancy is $\geq 5$ years.

The benefit of CEA is established in the presence of a perioperative death or stroke rate of $<6 \%$ for symptomatic and $<3 \%$ for asymptomatic patients. The 2005 guidelines of the American Academy of Neurology recommend revascularization in eligible asymptomatic patients only up to the age of 75 years [26].

\section{Carotid Artery Stenting Randomized Trials of Carotid Endarterec- tomy Versus Carotid Artery Stenting}

Four major (i.e., including over 300 patients) clinical trials randomizing patients to CEA or carotid artery stenting (CAS) have been published. While the SAPPHIRE (Stenting and Angioplasty with Protection in Patients at HIgh Risk for Endarterectomy) trial [27] focused on patients - both symptomatic and asymptomatic - at high risk for surgery, CAVATAS (CArotid and Vertebral Artery Transluminal Angioplasty Study [28]), SPACE (Stent-protected Percutaneous Angioplasty of the Carotid artery versus Endarterectomy) [29], and EVA-3S (Endarterectomy Versus Angioplasty in patients with Symptomatic Severe carotid Stenosis [30]) exclusively enrolled symptomatic patients.

CAVATAS, performed in the late 1990s, randomized 504 symptomatic patients at low to moderate risk for surgery to CEA or carotid angioplasty [28]. The incidence of death or stroke at 30 days was $10.0 \%$ in the endovascular group and $9.9 \%$ in the surgical group. The outcomes among the two groups remained comparable at 3 years. The study has been criticized by the interventionalist community for the low stenting rate $(26 \%)$ and the lack of emboli protection devices (EPDs) - unavailable at that time and by the surgeons for the high event rates in the surgical arm.

The SAPPHIRE study is the only randomized trial comparing CEA and CAS performed with the systematic use of EPDs [27]. The trial included symptomatic and asymptomatic patients at high risk for surgery and was designed to prove the noninferiority of the endovascular approach. The study was terminated prematurely because of slow enrollment due to competing CAS registries. Among the 334 patients randomized ( $29 \%$ of them being symptomatic), major adverse events at 1 year occurred in $12.2 \%$ in the CAS group and in $20.1 \%$ in the CEA group $(\mathrm{p}=0.053)$. In the actual treatment analysis the observed difference reached statistical significance $(\mathrm{p}=0.048)$. The need for repeat carotid revascularization at 1 year was lower in the CAS group $(0.6 \%$ vs. $4.3 \% ; p=0.04)$. No cranial nerve injury was observed in the CAS group while this complication occurred in $5.3 \%$ of the CEA patients $(\mathrm{p}<0.01)$. For the first time nonfatal ischemic cardiac events were included in the outcome analysis of a carotid revascularization trial. Patients who underwent CAS had significantly fewer myocardial infarctions at 30 days compared with those who were randomized to CEA $(1.9 \%$ vs. $6.6 \% ; p=0.04)$. The mean length of hospital stay was 1.8 days in the CAS group and 2.8 days in the CEA group ( $\mathrm{p}=$ 0.002 ). The durability of CAS was documented by a comparable cumulative percentage of major $(1.3 \%$ for CAS vs. $3.3 \%$ for CEA) and minor (6.1\% for CAS vs. $3.0 \%$ for CEA) ipsilateral strokes at 3 years as well as by a low rate of repeat revascularization during the same period of time $(3.0 \%$ for CAS vs. $7.1 \%$ for CEA) [31].

The SPACE study sought to prove the noninferiority of CAS compared with CEA among symptomatic patients. The use of EPDs in the CAS arm was left at the discretion of the treating physician. Although the required sample size based on interim analysis was $>2,400$ patients, the trial had to be terminated following the inclusion of 1,200 patients because of slow enrollment and lack of funding. The incidence of ipsilateral stroke or death at 30 days was the primary endpoint of the study and did not differ between the groups, occurring in $6.8 \%$ of cases in the endovascular group and in $6.3 \%$ of patients in the surgical arm [29].

EVA-3S was a randomized noninferiority trial comparing CAS with CEA in patients with a $\geq 60 \%$ symptomatic carotid artery stenosis. The primary endpoint was the cumulative incidence of any stroke or death within 30 days after treatment [30]. The trial was stopped prematurely after the inclusion of 527 patients because of significantly increased event rates in the CAS arm (death or stroke $9.6 \%$ in the CAS arm and $3.9 \%$ in the CEA arm; $p=0.01$ ). At 6 months, the incidence of any stroke or death was $11.7 \%$ in the CAS group and $6.1 \%$ in the CEA group $(p=0.02)$. The study has been heavily criticized for the inexperience of the interventionalists (a minimum of twelve CAS procedures was required). In a 
later correspondence, the investigators confirmed that $39 \%$ of patients were treated by physicians in training [32].

In summary, in patients at high surgical risk the SAPPHIRE study has demonstrated that CAS with adjunctive EPD is equal if not superior to surgery up to 1 year and that the results remain comparable at 3 years. The benefit of revascularization over optimal medical management in asymptomatic patients at high risk for endarterectomy is unknown because this question has never been addressed prospectively and the impact of asymptomatic carotid artery disease on the natural history of these patients is unknown. On a broader perspective, a meta-analysis of the four trials enrolling together over 2,500 patients - mostly symptomatic - was not able to detect the superiority of one revascularization strategy over the other (Figure 1).

\section{Strengths and Limitations of Carotid Artery Stenting}

The main advantage of CAS over CEA is that the endovascular approach is less invasive, performed in local anesthesia, and little influenced by comorbidities of the patient (Table 2). In addition, CAS may treat lesions that are not accessible to surgery (i.e., high in the internal carotid or low in the common carotid artery). Poor outcomes with CAS are usually related to challenging anatomies - such as a steep aortic arch or severe tortuosity of the common carotid arteries - as well as to poor femoral access. Although the procedure is feasible using a brachial or radial approach, the risk of complications increases in this setting. In the planning phase of a CAS, it is useful to obtain a CTA or MRA of supraaortic vessels including the aortic arch to estimate the procedural risk. As a general rule, if unexpected difficulties are encountered during engagement of the common carotid artery because of challenging anatomy, surgery should be reconsidered.

The inability to place an EPD should also be considered a relative contraindication to CAS. However, this is rarely the case because alternative approaches to filter-based EPDs - i.e., proximal occlusive devices - are available. Additional contraindications to CAS include a severe circumferential calcification at the level of the carotid lesion, which may limit stent expansion. In addition, for patients with severe renal insufficiency but not on dialysis or those with documented severe allergic reactions to angiographic contrast, CAS may not be the best option. Finally, for proven intolerance to aspirin or clopidogrel surgery should be preferred. In conclusion, proper patient selection in the planning of CAS is as critical as adequate training. Both an improp- 30-day death or stroke

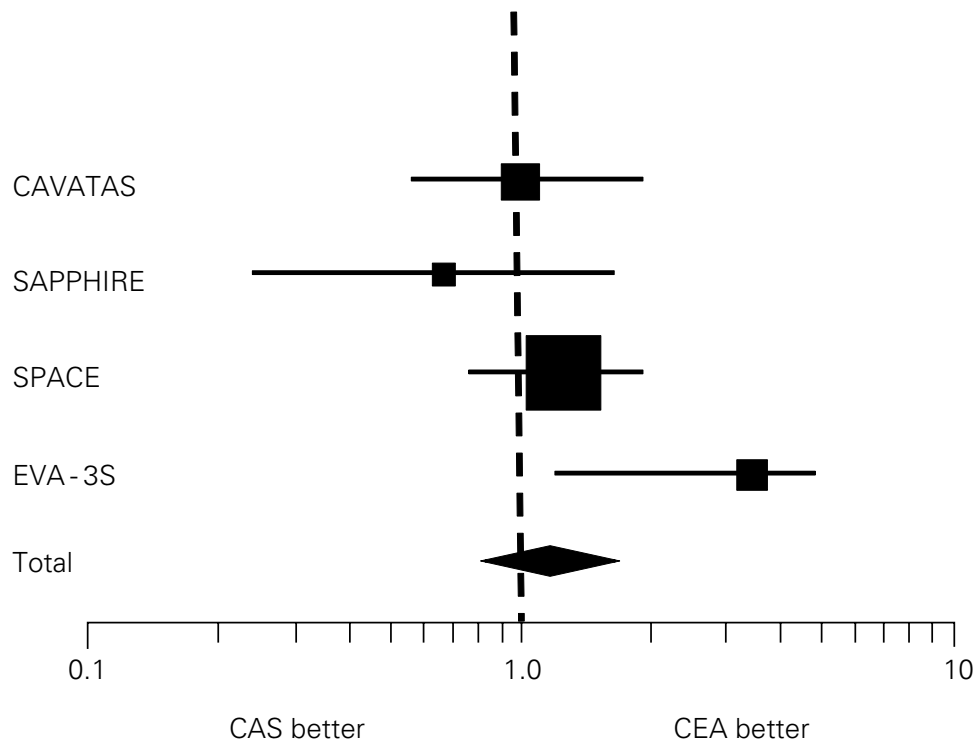

Figure 1. Meta-analysis of the four published randomized studies enrolling > 300 patients allocating patients to carotid artery stenting (CAS) or carotid endarterectomy (CEA; reproduced with permission from [36]).

Abbildung 1. Metaanalyse der vier publizierten Studien, die > 300 Patienten zu Endarteriektomie (CEA) oder Karotisstenting (CAS) randomisiert haben (mit Genehmigung abgedruckt aus [36]).

erly performed procedure and an adequately performed intervention on an inappropriate patient may result in a stroke, the very condition that CAS aims to prevent.

\section{Management Algorithm}

A crucial point when considering the best revascularization option for an individual patient is that high-risk conditions for CEA and CAS differ. Accordingly, while the outcomes of CEA are mainly influenced by the coexisting diseases, poor outcomes following CAS are usually related to challenging anatomies as well as to poor femoral access. A management algorithm for patients with suspected stenosis of the internal carotid artery is described in Figure 2. First of all, the degree of stenosis must be adequately assessed. For that purpose, it may be of advantage to have a second imaging modality in addition to DUS. Although randomized trials have documented the benefits of (surgical) revascularization in asymptomatic patients with carotid stenosis $\geq 60 \%$, in clinical practice asymptomatic lesions are often treated only if the degree of stenosis exceeds $70-80 \%$ and if the patient's life expectancy is at least 5 years. These considerations seem appropriate since the perioperative event rates commonly en- 
Figure 2. Suggested algorithm for the management of patients with suspected internal carotid artery stenosis (modified with permission from [35]). CAS: carotid artery stenting; CEA: carotid endarterectomy; DES: drug-eluting stent; EPD: emboli protection device.

Abbildung 2. Empfohlener Algorithmus für die Abklärung und Behandlung von Patienten mit Stenose der A. carotis interna (mit Genehmigung abgedruckt aus [35]). CAS: Karotisstenting; CEA: Karotisendarteriektomie; DES: Medikamente freisetzender Stent; EPD: Embolieprotektionssystem.

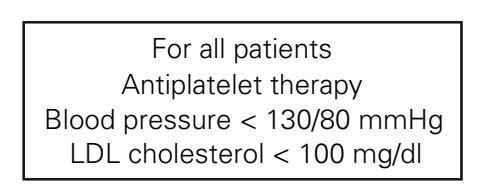

Suspected stenosis of the

internal carotid artery
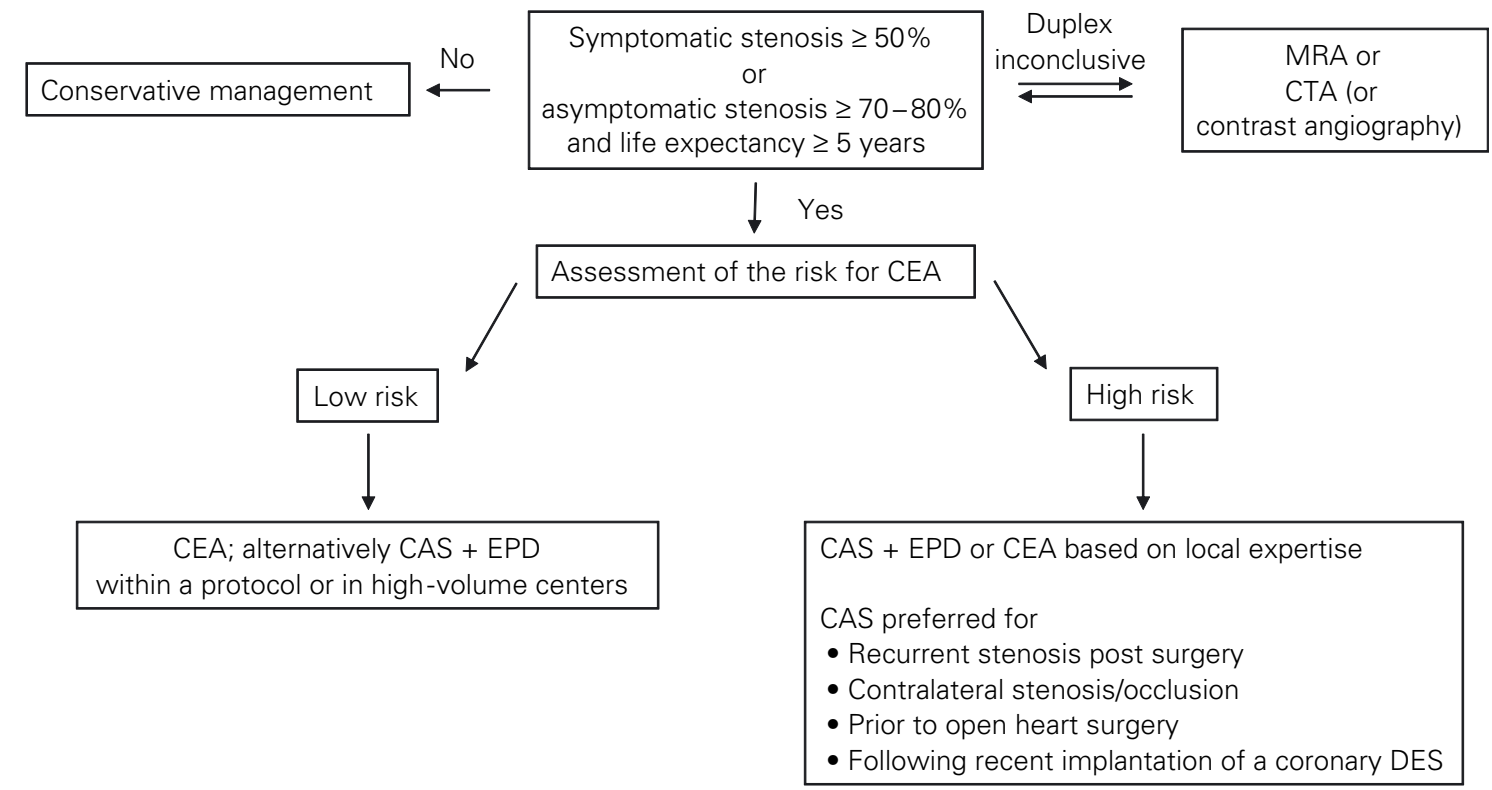

countered may be higher than those observed in the randomized trials $[22,23]$. Once the indication for revascularization is established, the surgical risk of the patient should be assessed. If the patient is at high risk for surgery, CAS with the use of EPDs may be the first choice, as long as the expertise is available and the patient does not have contraindications to CAS. Specifically, CAS is preferred for restenosis following CEA, in the presence of contralateral carotid occlusion, and in patients awaiting open heart surgery $[33,34]$. CAS should also been considered for patients who recently underwent coronary drug-eluting stent implantation as any surgical procedure - even if performed under aspirin and clopidogrel - may be associated with an increased risk of stent thrombosis. In patients at low risk for surgery, CEA may be the preferred strategy. Alternatively, those patients may be treated with CAS and EPD within study protocols or in high-volume centers.

\section{Conclusion}

A stenosis of the internal carotid artery may cause $10-20 \%$ of all ischemic strokes. DUS is the diagnostic cornerstone, and CTA or MRA may be used to confirm the severity of the stenosis or prior to revas- cularization. Catheter-based DSA is rarely needed for diagnostic purposes. In symptomatic patients, carotid revascularization is indicated in the presence of a stenosis $\geq 50 \%$. In asymptomatic patients, the indication for revascularization based on randomized trials is given at $\geq 60 \%$ stenosis, as long as the estimated perioperative death or stroke risk is $<3 \%$. In clinical practice, however, asymptomatic stenoses are usually treated only if luminal narrowing exceeds $70-80 \%$ and the patient has a life expectancy of at least 5 years. The choice of the revascularization strategy (CEA vs. CAS) should be based on the patient's surgical risk profile and on the locally available expertise. Independently of the revascularization option, carotid artery stenosis patients remain at risk of cardiovascular events because of the high prevalence of associated coronary artery disease. A broad disease management focusing on risk factor and lifestyle modification may impact quality and duration of life of these patients to a greater extent than the revascularization procedure itself.

Disclosure: The authors declare that they have no financial or personal relations to other parties whose interests could have affected the content of this article in any way, either positively or negatively. 


\section{References}

1. Fairhead JF, Rothwell PM. The need for urgency in identification and treatment of symptomatic carotid stenosis is already established. Cerebrovasc Dis 2005;19:355-8.

2. Inzitari D, Eliasziw M, Gates P, et al. The causes and risk of stroke in patients with asymptomatic internal-carotid-artery stenosis. N Engl J Med 2000;342:1693-700.

3. Halliday A, Mansfield A, Marro J, et al. Prevention of disabling and fatal strokes by successful carotid endarterectomy in patients without recent neurological symptoms: randomised controlled trial. Lancet 2004;363:1491-502.

4. Rothwell PM, Giles MF, Flossmann E, et al. A simple score $(A B C D)$ to identify individuals at high early risk of stroke after transient ischaemic attack. Lancet 2005;366:29-36.

5. Grant EG, Benson CB, Moneta GL, et al. Carotid artery stenosis: gray-scale and Doppler US diagnosis - Society of Radiologists in Ultrasound Consensus Conference. Radiology 2003;229:340-6.

6. Fayed AM, White CJ, Ramee SR, et al. Carotid and cerebral angiography performed by cardiologists: cerebrovascular complications. Catheter Cardiovasc Interv 2002;55:277-80.

7. Kragsterman B, Bjorck $M$, Lindback J, et al. Long-term survival after carotid endarterectomy for asymptomatic stenosis. Stroke 2006;37:2886-91.

8. Smith SC, Allen J, Blair SN, et al. AHA/ACC guidelines for secondary prevention for patients with coronary and other atherosclerotic vascular disease. Circulation 2006;113:2363-72.

9. Seo WK, Yong HS, Koh SB, et al. Correlation of coronary artery atherosclerosis with atherosclerosis of the intracranial cerebral artery and the extracranial carotid artery. Eur Neurol 2008;59:292-8.

10. Antithrombotic Trialists' Collaboration. Collaborative metaanalysis of randomised trials of antiplatelet therapy for prevention of death, myocardial infarction, and stroke in high risk patients. BMJ 2002;324:71-86.

11. Markus HS, Droste DW, Kaps M, et al. Dual antiplatelet therapy with clopidogrel and aspirin in symptomatic carotid stenosis evaluated using doppler embolic signal detection the Clopidogrel and Aspirin for Reduction of Emboli in Symptomatic carotid Stenosis (CARESS) trial. Circulation 2005;111:2233-40.

12. Junghans $\mathrm{U}$, Siebler M. Cerebral microembolism is blocked by tirofiban, a selective nonpeptide platelet glycoprotein Ilb/IIla receptor antagonist. Circulation 2003;107:2717-21.

13. Heart Protection Study Collaborative Group. MRC/BHF Heart Protection Study of cholesterol lowering with simvastatin in 20,536 high-risk individuals: a randomised placebo-controlled trial. Lancet 2002;360:7-22.

14. Amarenco P, Bogousslavsky J, Callahan A, et al. High-dose atorvastatin after stroke or transient ischemic attack. N Engl J Med 2006;355:549-59.

15. Yusuf S, Sleight P, Pogue J, et al. Effects of an angiotensin-converting-enzyme inhibitor, ramipril, on cardiovascular events in high-risk patients. N Engl J Med 2000;342:145-53.

16. Dahlof B, Devereux RB, Kjeldsen SE, et al. Cardiovascular morbidity and mortality in the Losartan Intervention For Endpoint reduction in hypertension study (LIFE): a randomised trial against atenolol. Lancet 2002;359:995-1003.

17. North American Symptomatic Carotid Endarterectomy Trial Collaborators. Beneficial effect of carotid endarterectomy in symptomatic patients with high-grade carotid stenosis. N Engl J Med 1991;325:445-53.

18. Barnett HJ, Taylor DW, Eliasziw M, et al. Benefit of carotid endarterectomy in patients with symptomatic moderate or severe stenosis. N Engl J Med 1998;339:1415-25.
19. Halliday A, Mansfield A, Marro J, et al. Prevention of disabling and fatal strokes by successful carotid endarterectomy in patients without recent neurological symptoms: randomised controlled trial. Lancet 2004;363:1491-502.

20. Rothwell PM, Eliasziw M, Gutnikov SA, et al. Analysis of pooled data from the randomised controlled trials of endarterectomy for symptomatic carotid stenosis. Lancet 2003;361:107-16.

21. Endarterectomy for asymptomatic carotid artery stenosis. Executive Committee for the Asymptomatic Carotid Atherosclerosis Study. JAMA 1995;273:1421-8.

22. Wennberg DE, Lucas FL, Birkmeyer JD, et al. Variation in carotid endarterectomy mortality in the Medicare population: trial hospitals, volume, and patient characteristics. JAMA 1998;279:1278-81.

23. Tu JV, Wang H, Bowyer B, et al. Risk factors for death or stroke after carotid endarterectomy: observations from the Ontario Carotid Endarterectomy Registry. Stroke 2003;34: 2568-73.

24. Birkmeyer JD, Stukel TA, Siewers AE, et al. Surgeon volume and operative mortality in the United States. N Engl J Med 2003;349:2117-27.

25. Biller J, Feinberg WM, Castaldo JE, et al. Guidelines for carotid endarterectomy: a statement for healthcare professionals from a Special Writing Group of the Stroke Council, American Heart Association. Circulation 1998;97:501-9.

26. Chaturvedi S, Bruno A, Feasby T, et al. Carotid endarterectomy - an evidence-based review: report of the Therapeutics and Technology Assessment Subcommittee of the American Academy of Neurology. Neurology 2005;65:794-801.

27. Yadav JS, Wholey MH, Kuntz RE, et al. Protected carotid-artery stenting versus endarterectomy in high-risk patients. N Engl J Med 2004;351:1493-501.

28. CAVATAS Investigators. Endovascular versus surgical treatment in patients with carotid stenosis in the CArotid and Vertebral Artery Transluminal Angioplasty Study (CAVATAS): a randomised trial. Lancet 2001;357:1729-37.

29. Ringleb PA, Allenberg J, Bruckmann $\mathrm{H}$, et al. 30 day results from the SPACE trial of stent-protected angioplasty versus carotid endarterectomy in symptomatic patients: a randomised non-inferiority trial. Lancet 2006;368:1239-47.

30. Mas JL, Chatellier G, Beyssen B, et al. Endarterectomy versus stenting in patients with symptomatic severe carotid stenosis. N Engl J Med 2006;355:1660-71.

31. Gurm HS, Yadav JS, Fayad P, et al. Long-term results of carotid stenting versus endarterectomy in high-risk patients. N Engl J Med 2008;358:1572-9.

32. Maree AO, Rosenfield KA. Endarterectomy versus stenting for carotid stenosis. N Engl J Med 2007;356:306, author reply 306-7.

33. Bates ER, Babb JD, Casey DE, et al. ACCF/SCAI/SVMB/SIR/ ASITN 2007 clinical expert consensus document on carotid stenting: a report of the American College of Cardiology Foundation Task Force on Clinical Expert Consensus Documents. J Am Coll Cardiol 2007;49:126-70.

34. Roffi M. Management of patients with concomitant severe coronary and carotid artery disease: is there a perfect solution? Circulation 2007;116:2002-4.

35. Roffi M, Yadav JS. Carotid stenting. Circulation 2006;114 e1-4.

36. Roffi M, Abou-Chebl A, Mukherjee D. Principles of carotid artery stenting. Bremen: Uni-Med, 2008.

\section{Address for Correspondence}

Marco Roffi, MD

Director, Interventional Cardiology Unit

Division of Cardiology University Hospital Rue Michelidu-Crest 24 1211 Geneva Switzerland Phone $(+41 / 22)$ 3727-208, Fax -229 e-mail: Marco. Roffi@hcuge.ch 